\title{
Multicomponent Povarov reaction catalyzed by $\mathrm{NbCl}_{5}$.
}

\section{Bruno Henrique Sacoman Torquato da Silva, ${ }^{1, *}$ Lụcas Michelão Martins ${ }^{1}$ e Luiz Carlos da Silva-Filho}

\author{
${ }^{1}$ Chemistry Departament, Faculty of Sciences, UNESP-Bauru, Av. Eng. Luiz Edmundo Carrijo Coube, 14-01, \\ CEP 17033-360, Vargem Limpa, Bauru, S.P. *e-mail: bruno sacoman@hotmail.com
}

Keywords: Niobium Pentachloride, Multicomponent Povarov reaction, Tetrahydroquinolines derivative.

\section{INTRODUCTION}

Recent studies in literature show efficiency of tetrahydroquinolines derivatives (1) as an anticancer agent, acting in the inhibition of certain enzymes that are essential in the cellular division. ${ }^{1}$ Tetrahydroquinolines derivatives also showed activity in the treatment of Alzheimer's Disease by inhibiting the enzyme acetylcholinesterase, an enzyme needed for nerve impulse transmission and responsible for the degradation of acetilchlorine. ${ }^{2}$

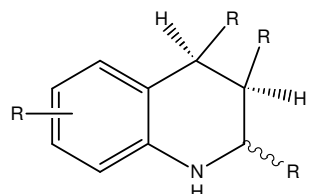

1

Figure 1. Tetrahydroquinoline Derivative.

Tetrahydroquinolines derivatives can be synthesized from the Multicomponent Povarov reaction (MCR) in the presence of different catalysts $\left(\mathrm{GdCl}_{3}, \mathrm{SbCl}_{3}, \mathrm{Sml}_{2}, \mathrm{VCl}_{3} \text { and others }\right)^{3}$

\section{RESULTS AND DISCUSSION}

In this work, we performed the Multicomponent Povarov Reaction between aniline (2), Benzaldehyde (3) and different dienophiles, such as 2,3-dihydrofuran (4), 3,4-dihydropyran (5), cyclopentenone (6) and cyclohexenone (7) in the presence of $\mathrm{NbCl}_{5}$. The reactions were carried out under nitrogen atmosphere, at room temperature and in anhydrous solvent $\left(\mathrm{CH}_{3} \mathrm{CN}\right)$, varying the concentration of $\mathrm{NbCl}_{5}$ (10 and $25 \mathrm{~mol} \%$ ). The products were isolated and characterized by spectroscopic and spectrometric methods.

The reaction proceeded smoothly at room temperature to afford corresponding tetrahydroquinolines, in $54-85 \%$ yield. The products were obtained as a mixture of cis and trans isomers, which were separated by column chromatography. The product ratio was determined by ${ }^{1} \mathrm{H}$ NMR spectra. The results are summarized in scheme 1 and table 1.
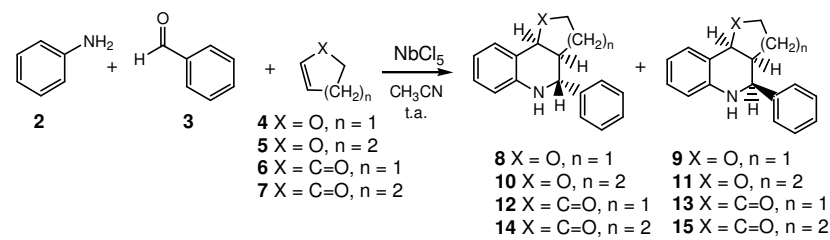

Scheme 1. MCRs of Povarov catalyzed by $\mathrm{NbCl}_{5}$.

Table 1. Results obtained in Multicomponents Povarov reactions in the presence of $\mathrm{NbCl}_{5}$.

\begin{tabular}{ccccc}
\hline dienophile & $\begin{array}{c}\% \\
\mathrm{NbCl}_{5}\end{array}$ & Time $(\mathrm{min})$ & $\begin{array}{c}\text { Yield } \\
(\%)\end{array}$ & $\begin{array}{c}\text { Products ratio } \\
(\%)\end{array}$ \\
\hline $\mathbf{4}$ & 10 & 30 & 70 & $11: 89(\mathbf{8 : 9})$ \\
\hline $\mathbf{5}$ & 10 & 30 & 85 & $05: 95(\mathbf{1 0 : 1 1})$ \\
\hline $\mathbf{6}$ & 10 & 50 & 52 & $85: 15(\mathbf{1 2 : 1 3})$ \\
\hline $\mathbf{7}$ & 10 & 30 & 54 & $79: 21(\mathbf{1 4}: \mathbf{1 5})$ \\
\hline $\mathbf{4}$ & 25 & 15 & 71 & $25: 75(\mathbf{8}: 9)$ \\
\hline $\mathbf{5}$ & 25 & 20 & 80 & $15: 85(\mathbf{1 0}: 1 \mathbf{1 1})$ \\
\hline $\mathbf{6}$ & 25 & 30 & 54 & $71: 29(\mathbf{1 2 : 1 3})$ \\
\hline $\mathbf{7}$ & 25 & 20 & 56 & $66: 34(\mathbf{1 4}: \mathbf{1 5})$ \\
\hline
\end{tabular}

Similarly, aniline and benzaldehyde react with cyclic enol ethers and cycloalkenones to yield respective tetrahydroquinoline derivatives, with good reactional times and moderate yields.

\section{CONCLUSION}

In conclusion, we describe a novel, efficient, and practical methodology for the preparation of tetrahydroquinolines derivatives through Multicomponent Povarov reaction. The method offers several advantages such as mild reaction conditions, good reactional times, cleaner reaction products, compared to others catalyst. ${ }^{3}$

\section{ACKNOWLEDGEMENTS}

The authors thanks to FAPESP and PROPe-UNESP for financial support. We also thank CBMM for $\mathrm{NbCl}_{5}$ samples.

\section{REFERENCES}

${ }^{1}$ (a) Gore, V. K.; et al. Bioorg. Med. Chem . Lett. 2010, 20, 3573

2 (b) Schiemann, K.; et al. Bioorg. Med. Chem . Lett. 2010, 20, 1491; (c) Camps, P.; et al. J. Med. Chem. 2009, 52, 5365.

${ }^{2}$ (a) Ma, Y.; et al. J. Org. Chem. 2009, 64, 6462.; (b) Zhou, Z.; et al. Eur. J. Org. Chem. 2007, 5265.; (c) Semwal, A.; et al. Synth, Communs. 2006. 36 227. (d) Mahajan, D.; et al. Tetrahedron Lett. 2006, 7919. 